\title{
Implementation of Unified Power Quality Conditioner Based on Variable Phase Angle Control Method
}

\author{
Dr. G. Raja Rao (Head of the Department) \\ Department of Electrical Engneering, \\ Anil Neerukonda Institute Of Technology And Sciences, Visakhapatnam-531162,A.P,India \\ L.Dinesh (Assistant Professor) \\ Department of Electrical Engineerng, \\ Anil Neerukonda Institute of Technology And Sciences, Visakhapatnam-531162,A.P,India \\ Sk.Ahamadi (Btech final year) \\ Department of Eletrical Engineering,ANITS
}

\begin{abstract}
This paper investigates the power quality problems which occur frequently in power supply and suggests a method to mitigate the power quality problems by the implementation of UPQC. P-Q problems generally concern with voltage sags/swells and harmonic currents. Custom Power (CP) devices that mitigate these power quality problems have gained more attention in the recent decades. UPQC is Designed, modelled and setup experimentally to mitigate voltage sag/swells and harmonic currents in three phase systems. UPQC consists of Dynamic Voltage Restorer (DVR) and Active Power Filter (APF). UPQC with proposed controller algorithms effectively compensates the sag/swell in supply voltage by keeping the load voltage amplitude at $0.9-1$ per unit and eliminates the load current harmonics by keeping supply current at 5\% less than of Total Harmonic Distortion, simultaneously.
\end{abstract}

Keywords: Custom power device,Voltage sag,swell,Harmonics.

DOI: $10.7176 / \mathrm{ISDE} / 12-3-03$

Publication date:September $30^{\text {th }} 2021$

\section{Introduction}

Power Quality (PQ) has become an important issue to electricity consumers at all levels of usage. The PQ issue is defined as "Any power problem manifested in voltage, current, or frequency deviations that results in failure or disoperation of customer equipment." The development of power electronic based equipment has a significant impact on quality of electric power supply. The switch mode power supplies (SMPS), dimmers, current regulator, frequency converters, low power consumption lamps, arc welding machines, etc., are some out of the many vast applications of power electronics based devices. The operation of this loads/equipment generates harmonics and thus, pollutes the modern distribution system.

The growing interest in the utilization of renewable energy resources for electric power generation is making the electric power distribution network more susceptible to power quality problems. In such conditions both electric utilities and end users of electric power are increasingly concerned about the quality of electric power.Thus Upqc came into limelight. UPQC is design to improve power quality of 3 phase and 4 wire system. It is the combination of software and hardware.

\section{UPQC}

A Unified Power Quality Conditioner - UPQC results from the joint operation of a series active conditioner and a shunt active conditioner. The UPQC aggregates in single equipment the current compensation capabilities of a shunt active power filter and the voltage compensation capabilities of a series active filter, allowing the mitigation of both current- and voltage-related problems simultaneously. The main purpose of a UPQC is to compensate for supply voltage flicker/imbalance, reactive power, negative-sequence current, and harmonics. In other words, the UPQC has the capability of improving power quality at the point of installation on power distribution systems or industrial power systems. 


\subsection{Basic Representation of UPQC}

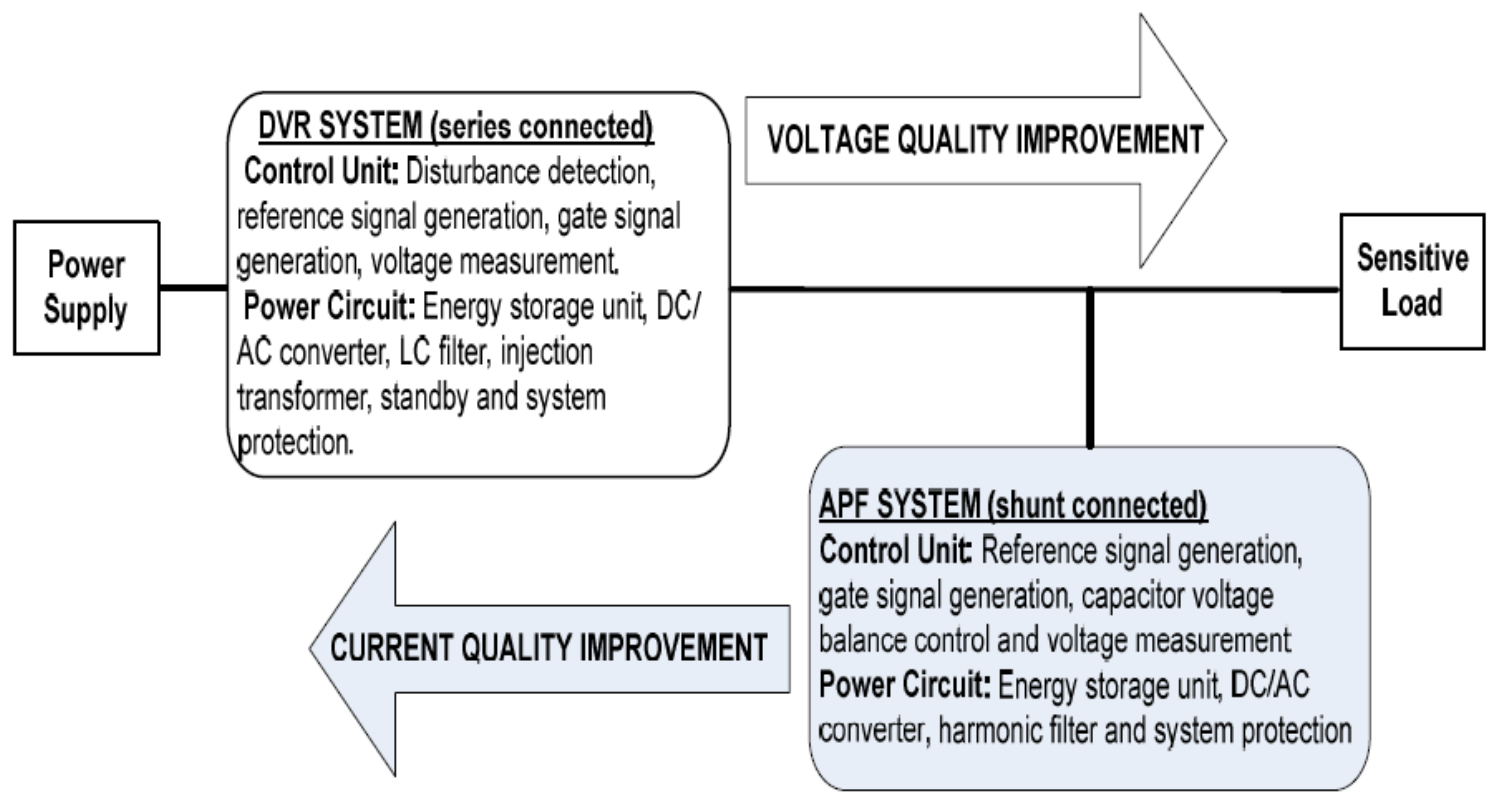

Fig. 1 flow diagram of UPQC

UPQC is a combination of a shunt (Active Power Filter) and a series compensator (Dynamic Voltage Restorer) connected together via a common DC link capacitor, which facilitates the sharing of the active power. Each compensator consists of IGBT inverters, which can be operated in current or voltage-controlled mode. Depending upon the location of the shunt compensator with respect to series compensator, UPQC model can be named as right shunt-UPQC or left shunt-UPQC.

\subsection{Block Diagram of UPQC}

UPQC generally consists of two voltage source inverters (series and shunt) using IGBT which operate from a common DC link storage capacitor. DC link (DC-DC converter) connected to the battery energy storage system is used in. Voltage interruption can also be eliminated by the use of a UPQC with distributed generation. The UPQC consists of two three phase inverters connected in cascade in such a manner that Inverter I is connected in series with the supply voltage through a transformer inverter II is connected in parallel with the load.

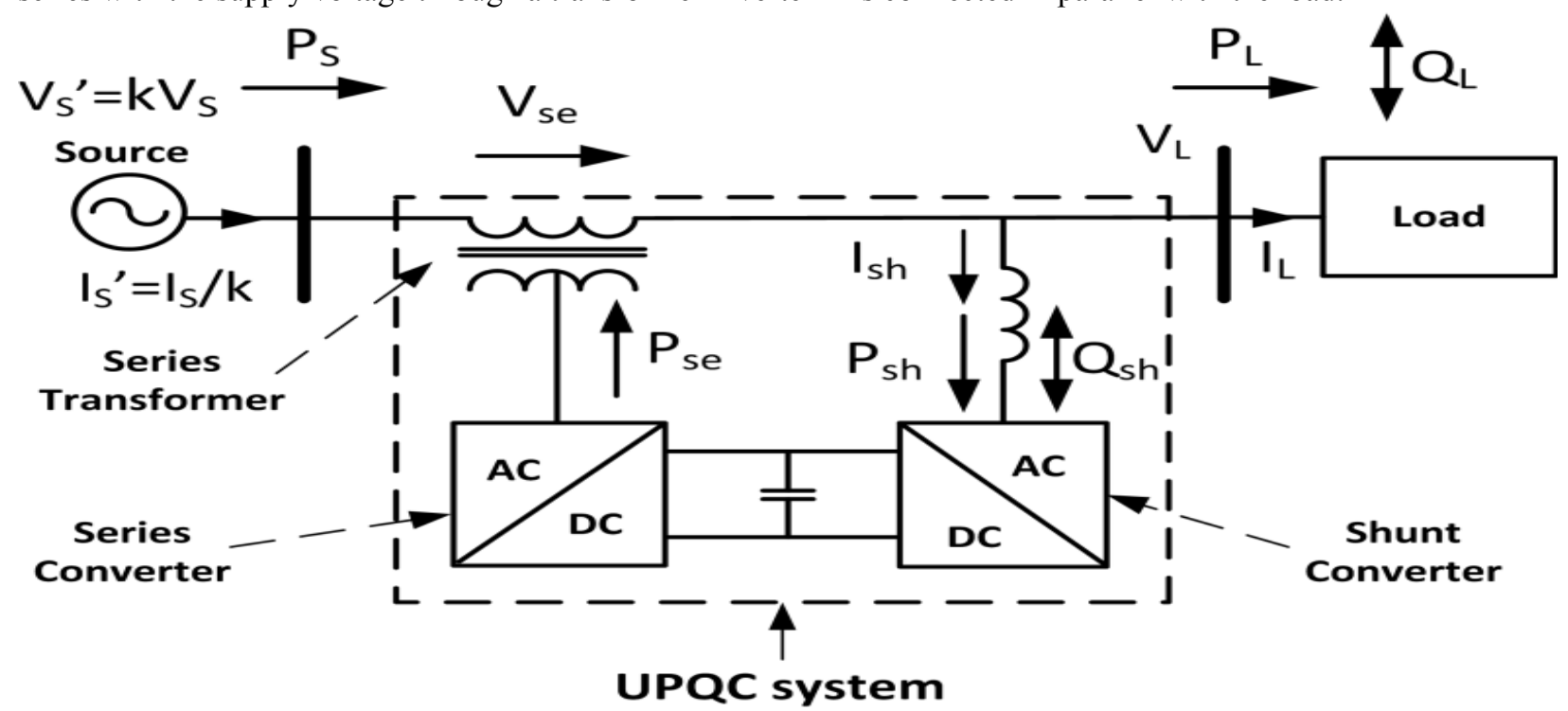

Fig.2 Block diagram of UPQC

The main purpose of the shunt compensator is to compensate for the reactive power demanded by the load, to eliminate the harmonics and to regulate the common dc link voltage. The series compensator is operated in PWM voltage-controlled mode. It injects voltage in quadrature advance to the supply voltage (current) such that the load end voltage is always maintained at the desired value. The two inverters operate in a coordinated manner. 


\subsection{Functions of UPQC}

- $\quad$ Convert the feeder (system) current into balanced sinusoids through the shunt compensator.

- $\quad$ Convert the load voltage VL to balanced sinusoids through the series compensator.

- $\quad$ Ensure zero real power injection (and/or absorption) by the compensators.

- $\quad$ Supply reactive power to the load (Q compensation).

\subsection{Overview After Implementation of UPQC}

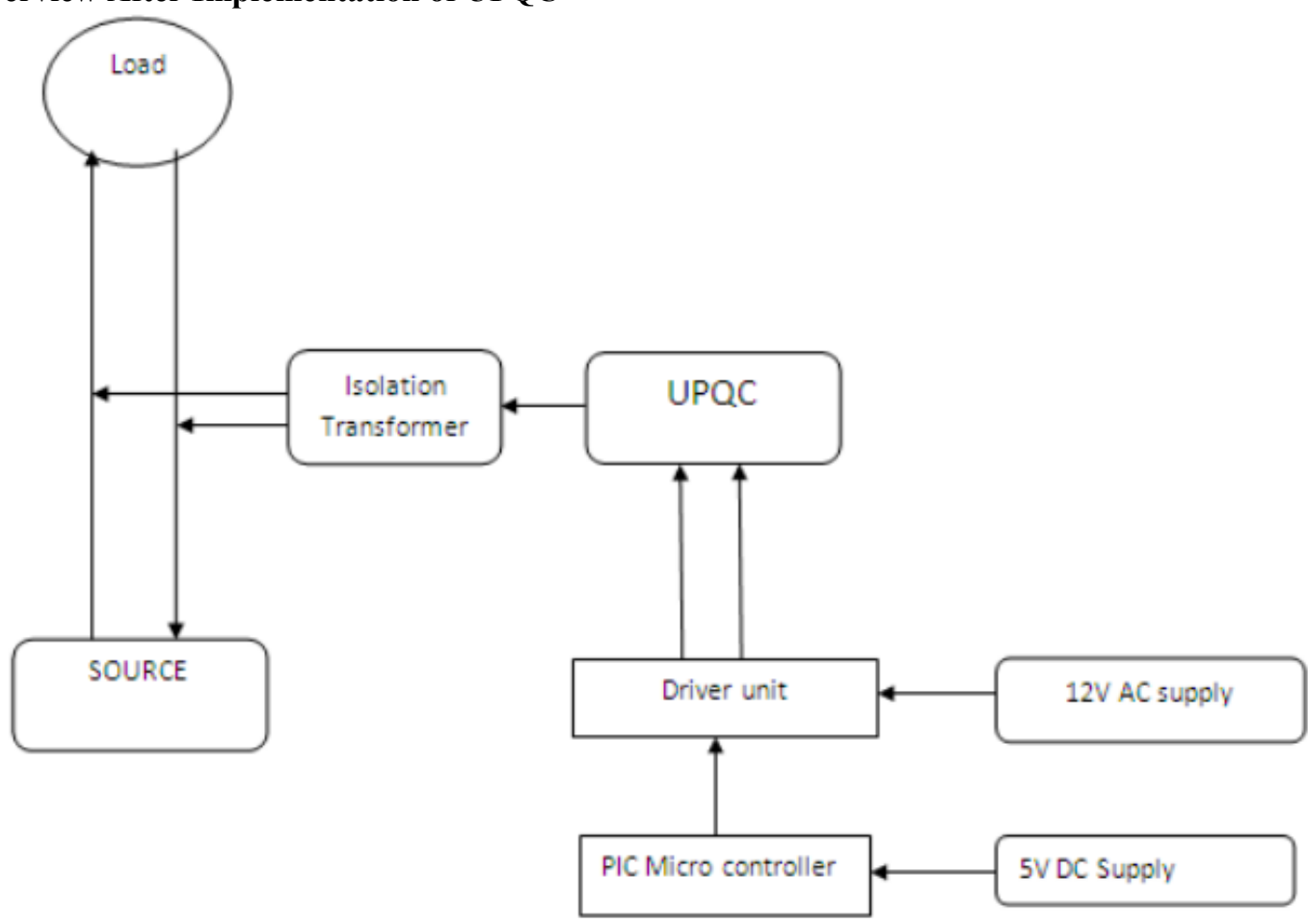

Fig.3 Block diagram of UPQC Control

\section{DESIGN OF UPQC USING MATLAB SIMULATION}

To verify the operating performance of the proposed UPQC, a 3-phase electrical system, a fuzzy logic controller with reference signal generation method is designed for UPQC and compared its performance with Artificial neural network based controller is simulated using MATLAB software.

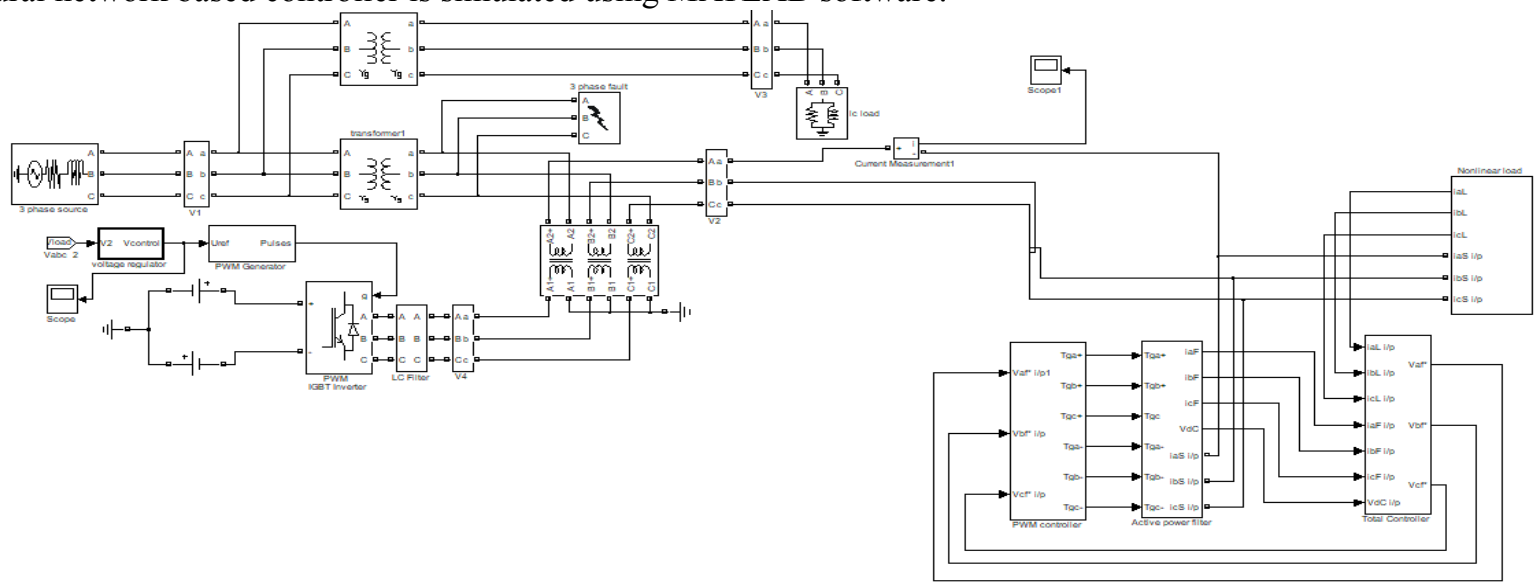

Fig. 4 Simulation circuit for upqc 


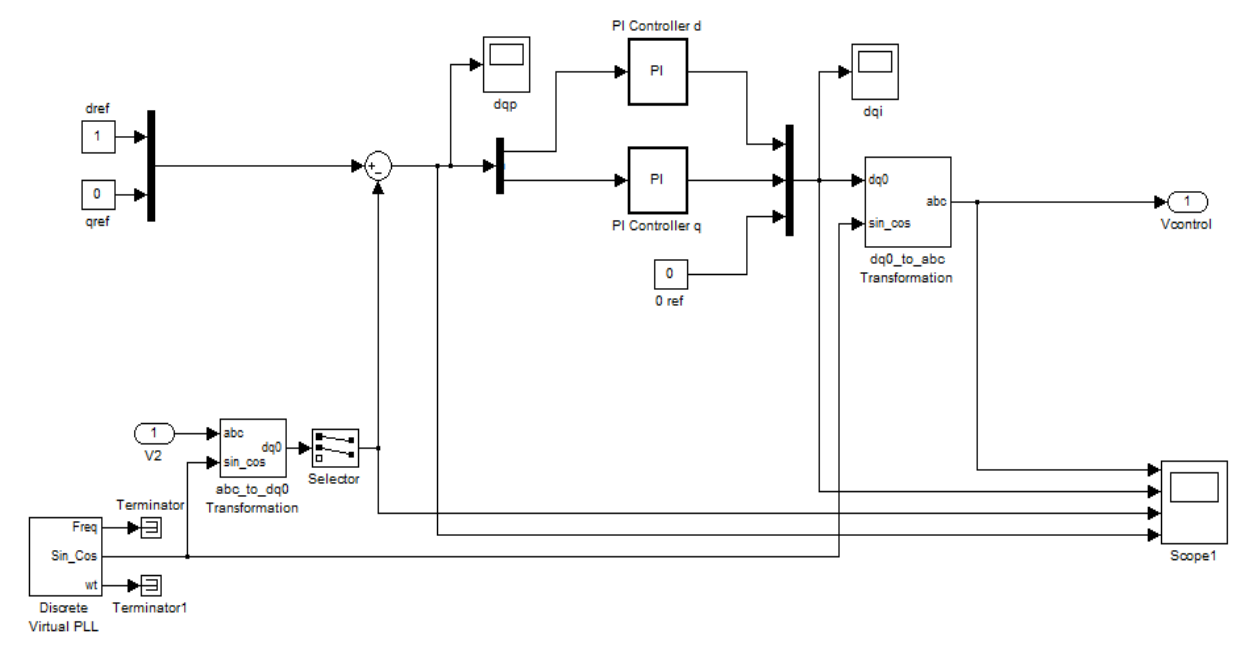

Fig. 5 Series filter control

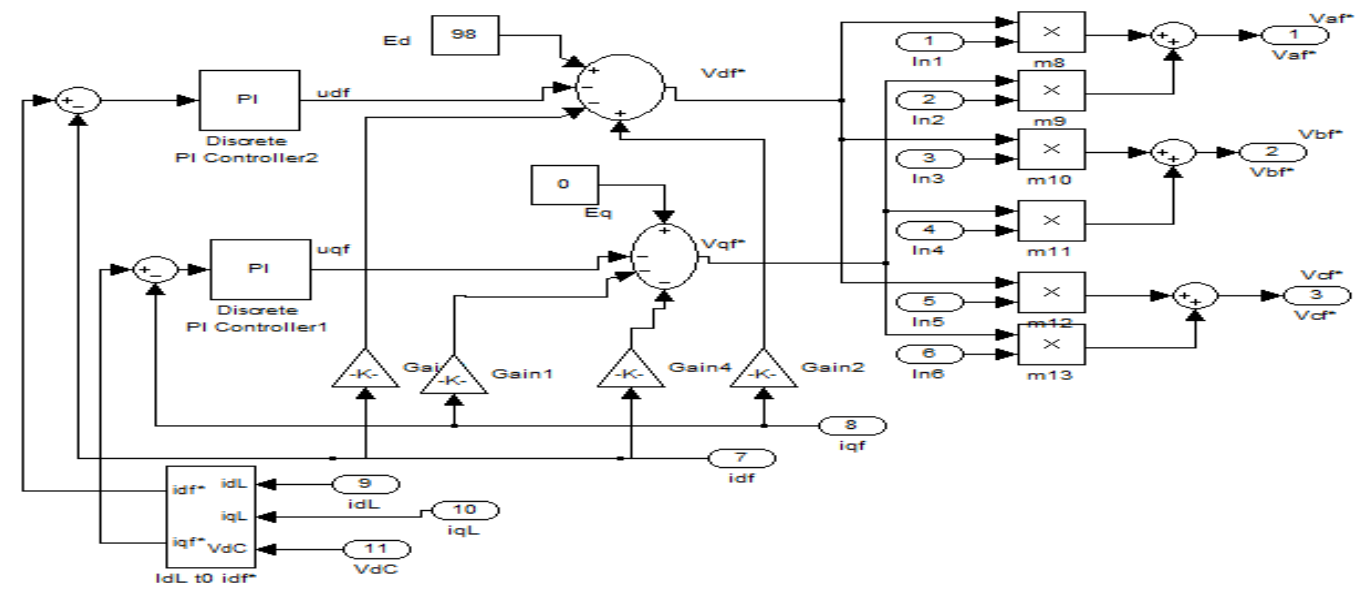

Fig. 6 Shunt filter control

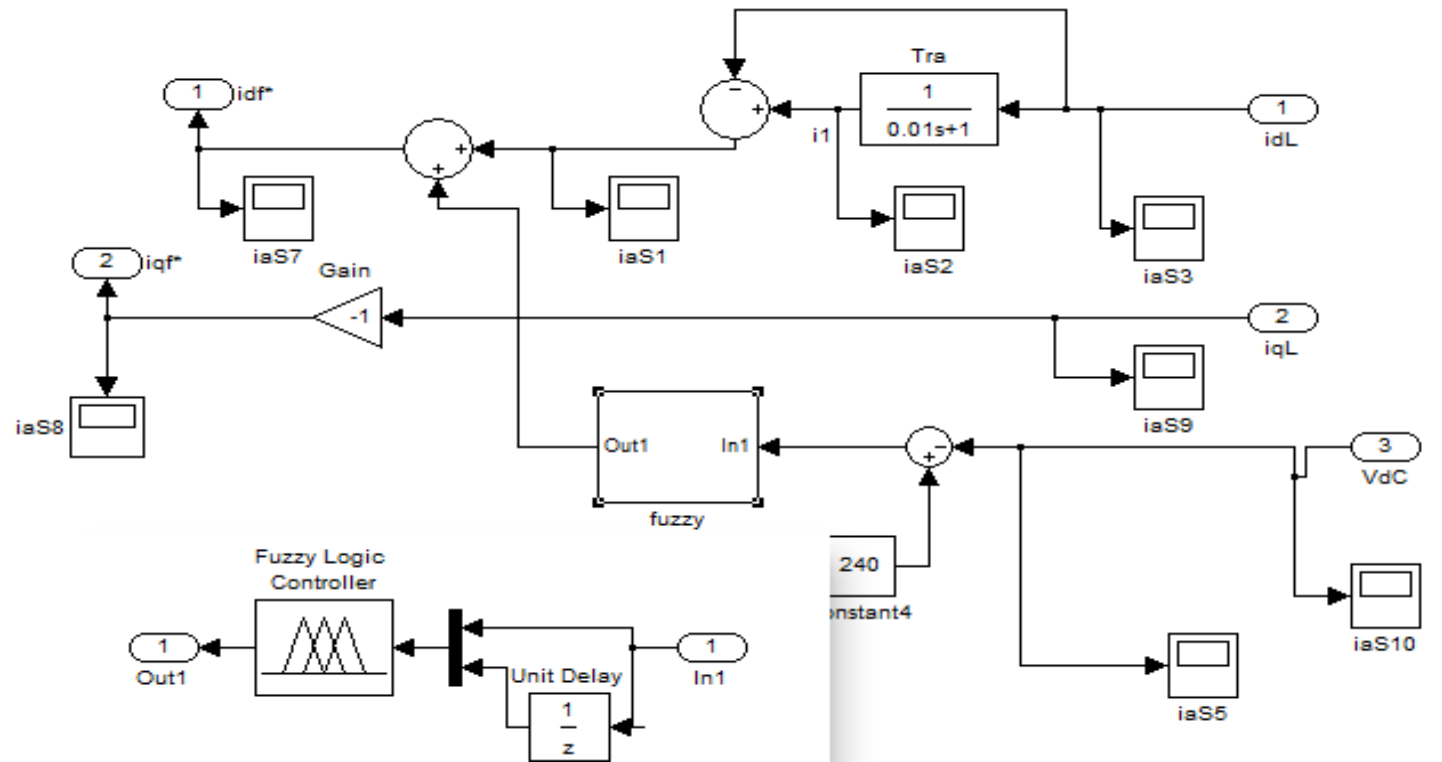

Fig. 7 Active filter with fuzzy controller 

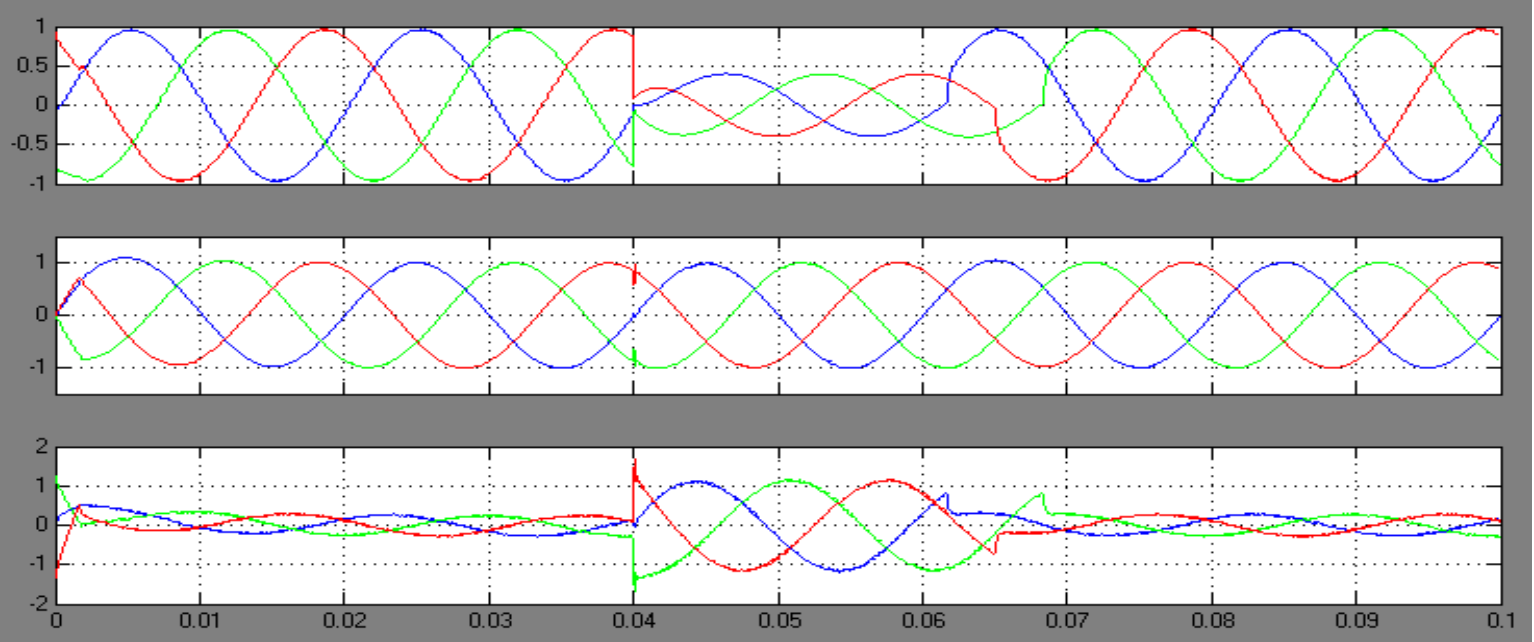

Fig. 83 phase fault and compensation by using series active power filter

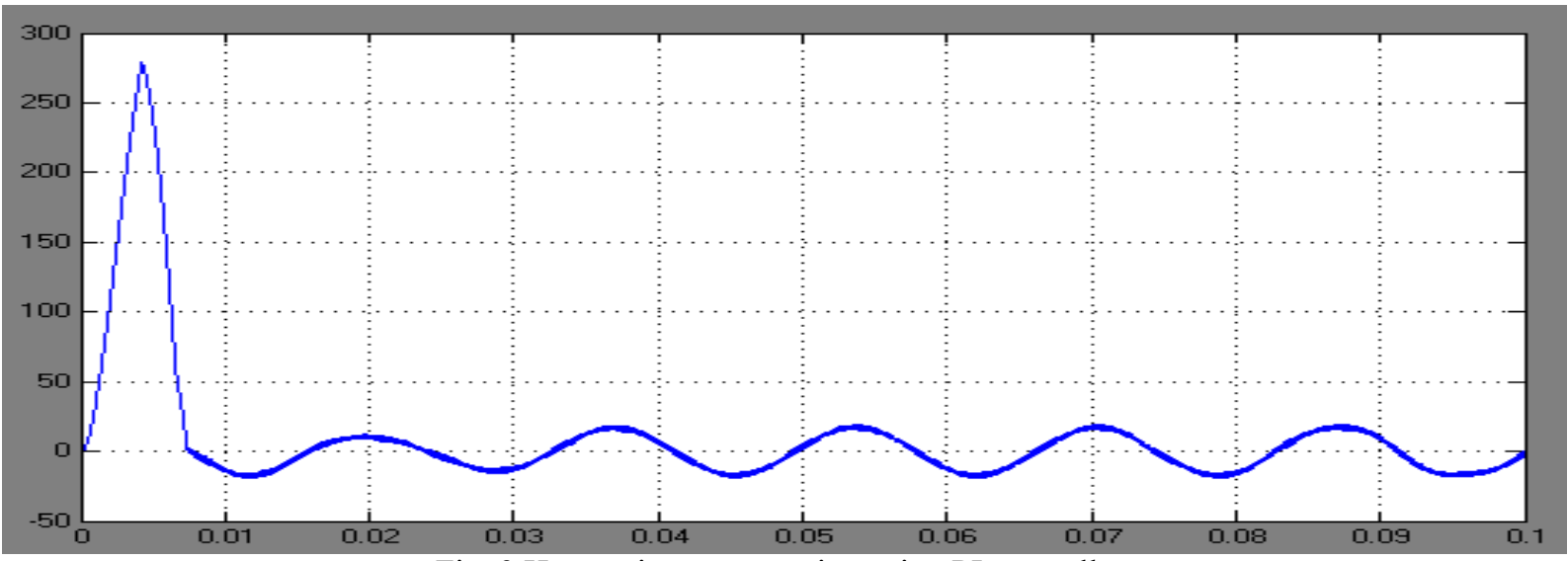

Fig. 9 Harmonic compensation using PI controller
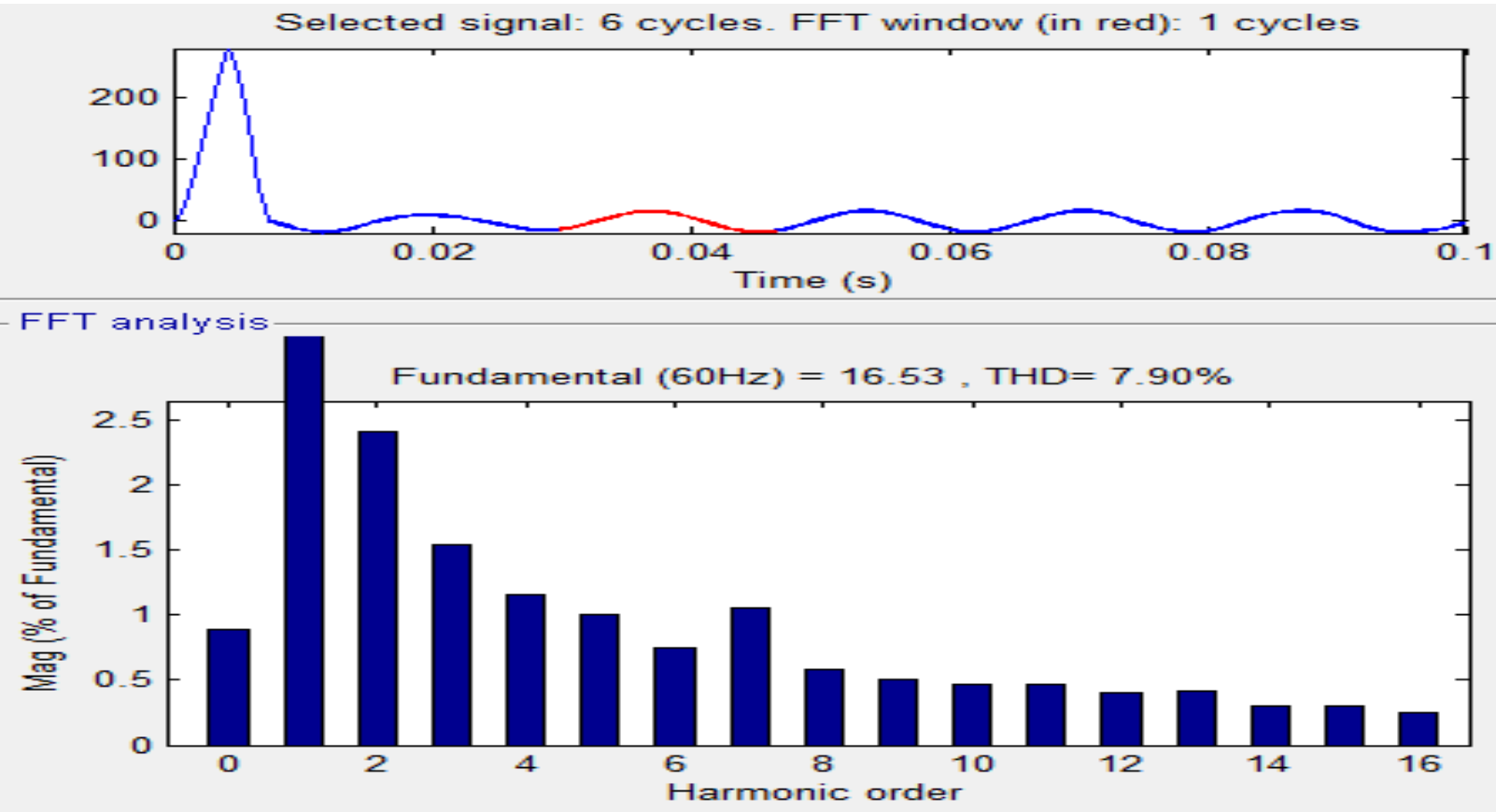

Fig. 10 THD using PI controller 

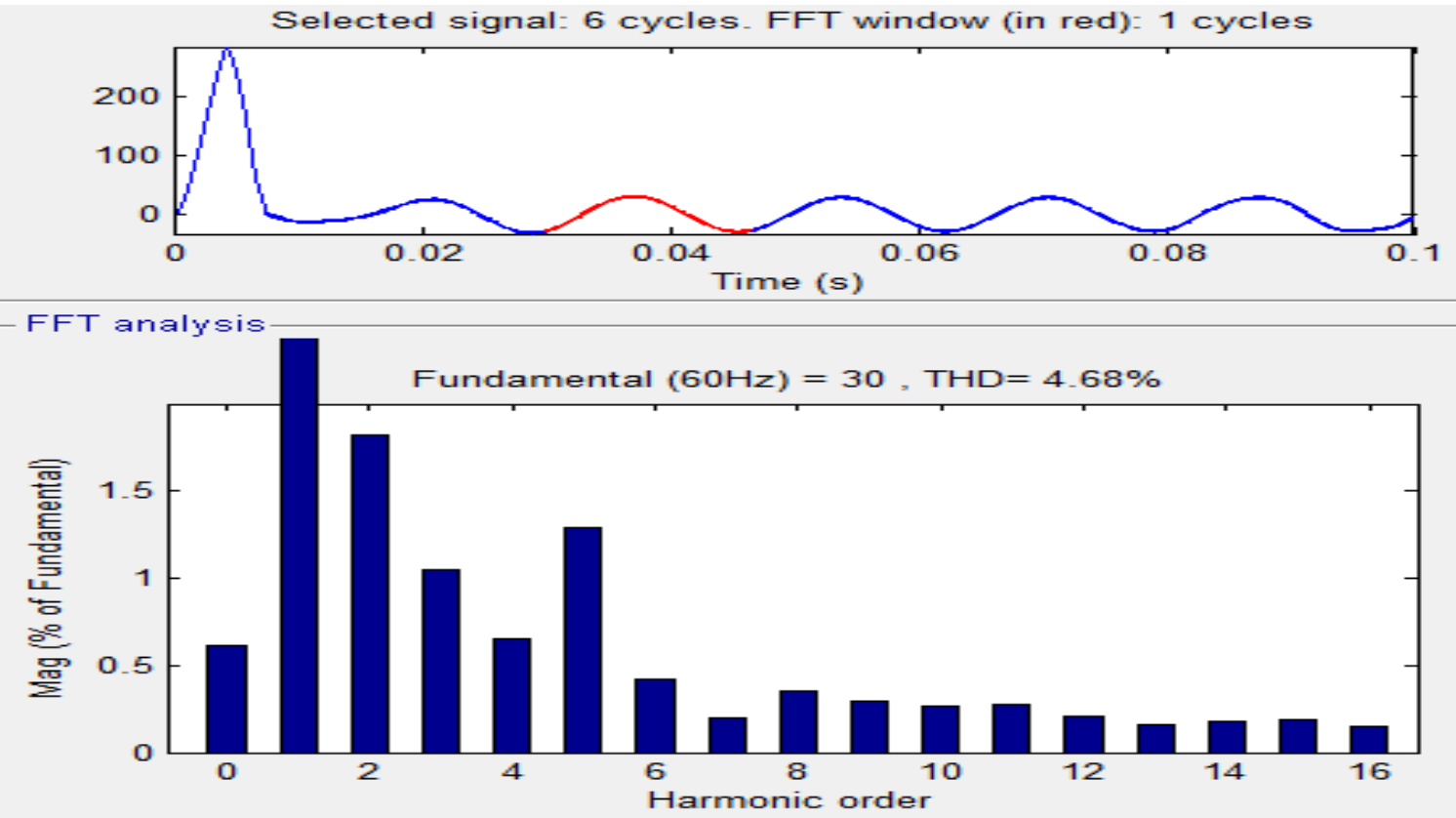

Fig 11. HD using fuzzy controller

\section{CONCLUSION}

This paper is mainly devoted to the study of Power Quality problems and its compensation with Unified power quality conditioner (UPQC). Results obtained from this study provide useful information regarding the behaviour of different controllers used for power quality improvement connected to distribution line. The controllers mainly used for power quality improvement are Fuzzy logic controller and Artificial neural network based controller. Hence as compared to the response obtained with Fuzzy controller, Neural network based controller have great advantage of flexibility. The improved capabilities of the integrated UPQC-UCES controller to rapidly control the dc voltage exchange.

\section{REFERENCES}

[1] Vadirajacharya G. Kinhal, Promod Agarwal, and Hari Oam Gupta (2011), Senior Member, IEEE "Performance Investigation of Neural-Network- Based Unified Power-Quality Conditioner" ieee transactions on power delivery, vol.26.

[2] Ahmet Teke, Lütfü Saribulut, and Mehmet Tümay (2011) “A Novel Reference Signal Generation Method for Power- Quality Improvement of Unified Power-Quality Conditioner" ieee transactions on power delivery.

[3] A. Zouidi, F. Fnaiech, and K. AL-Haddad (2006), "Neural network controlled three-phase three-wire shunt active power filter," in Proc. IEEE ISIE, Montreal, QC, Canada, Jul. 9-12,pp. 5-10.

[4 ]L. H. Tey, P. L. So, and Y. C. Chu (2004), "Unified power quality conditioner for improving power quality using ANN with hysteresis control," in Proc. Int. Conf. Power System Technology, pp. 1441-1446.

[5] Ruiye Liu, Ning Xia, Xiaonan Wang" The Research on Fuzzy-PID Control in Unified Power Quality Conditioner".

[6] Timothy Ross J. (1995), "Fuzzy Logic with Engineering Applications", McGraw-Hillbook Company; University of Mexico.

[7] HUANG Min, ZHA Xiao-ming, CHEN Yun-ping (2002), The controller of fuzzy changing structure of parallel power quality conditioner[J]. Power System Technology,26(7):11-14 